\title{
ÉPOCA DE COLHEITA DOS FRUTOS E OCORRÊNCIA DE DORMÊNCIA EM SEMENTES DE MAMÃO (Carica papaya L.) ${ }^{1}$
}

\author{
DAÍ TOKUHISA²; DENISE CUNHA FERNANDES DOS SANTOS DIAS ${ }^{3}$; EVELINE MANTOVANI ALVARENGA ${ }^{3}$; LUIZ ANTÔNIO DOS \\ SANTOS DIAS4; SÉRGIO LÚCIO DAVID MARIN 5
}

\begin{abstract}
RESUMO - O trabalho teve como objetivo relacionar a época de colheita dos frutos com a ocorrência de dormência nas sementes de mamão. Foram utilizados frutos de mamão do grupo Formosa, híbrido Tainung 01, colhidos no estádio 1 de maturação (até 15\% da superfície externa com coloração amarela) em cinco diferentes épocas do ano: Julho e Novembro/2004 e Fevereiro, Maio e Setembro/2005. Os frutos permaneceram armazenados em ambiente de laboratório até atingirem o estádio 5 de maturação (mais de $75 \%$ da superfície externa com coloração amarela). Em cada época, foram obtidas sementes com e sem sarcotesta, que foram submetidas ao teste de germinação, conduzido em germinador sob temperatura alternada de $20-30^{\circ} \mathrm{C}(16 \mathrm{~h} / 8 \mathrm{~h}$, respectivamente), avaliando-se a porcentagem de plântulas normais aos 15 e 30 dias após a semeadura. Verificou-se que a presença da sarcotesta na semente diminui a velocidade e a porcentagem de germinação. Houve efeito da época de colheita do fruto na germinação das sementes, sendo que as sementes extraídas de frutos colhidos em Julho/2004 e Maio/2005 apresentaram dormência pós-colheita, o que não ocorreu com as sementes obtidas de frutos que amadureceram em épocas de temperaturas mais altas.
\end{abstract}

Termos para indexação: maturação, colheita, germinação, Carica papaya L.

\section{FRUIT HARVEST SEASON AND DORMANCY OCCURRENCY IN PAPAYA SEEDS (Carica papaya L.)}

\begin{abstract}
This study was carried out in order to relate the fruit harvest season and dormancy occurrence in papaya seeds. Papaya fruits of the Formosa group, Tainung 01 hybrid, were harvested at maturation stage 1 (15\% external color yellow), at five different times: July and November/2004 and February, May and September/2005. The fruits were stored at room temperature until they reached maturation stage 5 (more than $75 \%$ external color yellow). Seeds with and without sarcotesta were obtained at each harvest time. Standard germination of these seeds was performed in a germinator at $20 / 30^{\circ} \mathrm{C}$ (8/16 hours, respectively) and normal seedlings percentage was evaluated at 15 and 30 days. Seeds with sarcotesta had lower germination speed and percentage. There was an effect of fruit harvest time on seed germination. Seeds extracted from fruits harvested in July/2004 and May/2005 had post-harvest dormancy, which did not occur in seeds from fruits harvested in the high temperature periods.
\end{abstract}

Index terms: maturation, harvest, germination, Carica papaya L.

${ }^{1}$ Submetido em 03/04/2007. Aceito para publicação em 19/02/2008. ${ }^{2}$ Eng. Agr., M.S., Depto. de Fitotecnia, Universidade Federal de Viçosa, 36570000 - Viçosa - MG. E-mail: daitokuhisa2004@yahoo.com.br; ${ }^{3}$ Prof. Adjunto, Depto. de Fitotecnia, , Universidade Federal de Viçosa, 36570-
000 - Viçosa - MG. E-mail: dcdias@ufv.br; eveline@ufv.br. ${ }^{4}$ Pesquisador, D..S., Depto. de Biologia Geral/BIOAGRO, Universidade Federal de Viçosa, 36570-000 - Viçosa - MG. E-mail: lasdias@ufv.br. ${ }^{5}$ Pesquisador, D.S., Empresa de Sementes Hera, 29000-060 - Linhares - ES. 


\section{INTRODUÇÃO}

O Brasil é o primeiro produtor mundial de mamão, com aproximadamente 1,6 milhões de toneladas, sendo um dos principais exportadores mundiais (Agrianual, 2005). A produção se concentra principalmente na Bahia e no Espírito Santo, com $49 \%$ e $37 \%$ de toda a produção brasileira, respectivamente (Agrianual, 2005).

A propagação do mamoeiro é feita por mudas obtidas de sementes que, frequentemente, apresentam germinação lenta e desuniforme, fato que tem sido atribuído à presença da sarcotesta, um envelope mucilaginoso que envolve externamente a semente (Gherardi e Valio, 1976; Pérez et al., 1980; Reyes et al., 1980; Chow e Lin, 1991; Schmildt et al., 1993). Segundo Reyes et al. (1980) e Chow e Lin (1991), a sarcotesta contém substâncias inibidoras que impedem ou dificultam a germinação das sementes. Assim, alguns trabalhos têm mostrado que a redução do tempo médio de germinação pode ser obtida pela simples remoção da sarcotesta das sementes (Pérez et al., 1980; Gherardi e Valio, 1976). Contudo, diversos autores verificaram que sementes desprovidas de sarcotesta também exibiram germinação baixa e irregular, atribuindo este comportamento à dormência póscolheita (Lange, 1961; Yahiro, 1979; Yahiro e Oryoji, 1980; Viggiano et al., 2000; Martins et al, 2005), embora os relatos referentes à ocorrência deste fenômeno em sementes de mamão não sejam conclusivos, uma vez que Singh e Singh (1981) e Santos et al. (1999) obtiveram germinação máxima em sementes logo após a colheita.

A dormência da semente é um importante estádio do ciclo de vida das plantas, sendo caracterizada pela ausência temporária da capacidade de germinação, permitindo que as espécies vegetais sobrevivam às adversidades, principalmente aquelas que dificultem ou impeçam o crescimento vegetativo da planta. Em contrapartida, constitui-se em um obstáculo para a agricultura, uma vez que gera desuniformidade na emergência das plântulas em campo (Dias, 2005). Assim, sementes dormentes não germinam logo após a colheita devido a mecanismos internos, de natureza física ou fisiológica, que bloqueiam a germinação, por período de tempo variável com o genótipo, com o estádio de maturação do fruto e com as condições de ambiente durante a maturação, dentre outros fatores (Baskin e Baskin, 1998; Cardoso, 2004).

Aroucha et al. (2005) verificaram que a época de desenvolvimento dos frutos e o armazenamento pós-colheita destes contribuíram para um aumento significativo da germinação das sementes de mamão. Constataram ainda que, a germinação das sementes de frutos recém-colhidos foi baixa e que as sementes de frutos colhidos em janeiro apresentaram germinação de $40 \%$, valor este superior ao obtido para as sementes colhidas em setembro $(14,75 \%)$, sendo que para frutos colhidos em janeiro foi necessário menor tempo de repouso para se obter máxima germinação das sementes quando comparados aos frutos colhidos em setembro. Na prática, também tem sido verificado que a intensidade de dormência destas sementes pode variar dependendo da época de maturação/colheita dos frutos. No entanto, as informações sobre o assunto disponíveis na literatura ainda são insipientes.

Neste contexto, este trabalho teve como objetivo relacionar a época de colheita dos frutos com a ocorrência de dormência em sementes de mamão.

\section{MATERIAL E MÉTODOS}

O trabalho foi conduzido no Laboratório de Sementes do Departamento de Fitotecnia da UFV, no período de Março de 2004 a Novembro de 2005. Foram utilizados frutos hermafroditas de mamão, do grupo Formosa, híbrido Tainung 01, produzidos pela empresa "Hidra e Hera Sementes", em Linhares, ES, colhidos sempre na mesma área de produção da empresa.

Os frutos foram colhidos no estádio 1 de maturação, apresentando a casca com até $15 \%$ da superfície externa com coloração amarela (Aroucha et al., 2004), em cinco diferentes épocas do ano, ou seja, Julho e Novembro/2004 e Fevereiro, Maio e Setembro/2005.

Após a colheita, os frutos permaneceram envolvidos em papel e armazenados em ambiente de laboratório até atingirem o estádio 5 de maturação (casca com mais de $75 \%$ da superfície externa com coloração amarela), conforme Aroucha et al. (2004). Em seguida, os frutos foram partidos ao meio e as sementes extraídas manualmente, lavadas em água corrente para a remoção dos resíduos de polpa. Uma porção das sementes (cerca de 500 sementes) foi colocada para secar em condição ambiente de laboratório, a $25^{\circ} \mathrm{C}$, até atingir grau de umidade de, aproximadamente, $12 \%$, obtendose, assim, uma amostra de sementes com a sarcotesta. As sementes restantes foram submetidas à fricção em peneira de arame com auxílio de uma escova de cerdas plásticas, sob jato de água corrente, para a remoção da sarcotesta, sendo, em seguida, colocadas para secar sobre papel toalha nas mesmas condições já descritas para as sementes com sarcotesta. Foram obtidas, então, sementes com e sem sarcotesta. 
A seguir, as sementes com e sem sarcotesta obtidas em cada época de colheita foram avaliadas quanto à germinação.

O teste de germinação das sementes de mamão foi realizado conforme descrito nas Regras para Análise de Sementes (Brasil, 1992). Foram utilizadas 4 repetições de 50 sementes semeadas em papel germitest, umedecido com volume de água equivalente a 2,5 vezes o peso do papel seco. Confeccionaram-se rolos que foram mantidos em germinador sob temperatura alternada de $20-30^{\circ} \mathrm{C}(16 \mathrm{~h} / 8 \mathrm{~h}$, respectivamente). As avaliações foram realizadas aos $15 \mathrm{e}$ 30 dias após a semeadura, sendo os resultados expressos em porcentagem média de plântulas normais.

\section{Procedimento estatístico}

O delineamento experimental utilizado foi o inteiramente casualizado com 4 repetições. Os dados obtidos para as sementes com e sem sarcotesta, em cada uma das cinco épocas de colheita (Julho e Novembro de 2004, Fevereiro, Maio e Setembro de 2005), foram submetidos à análise de variância, comparando-se as médias pelo teste $\mathrm{F}$, a $5 \%$ de probabilidade. Para tanto, foram apresentados gráficos de barra com os valores médios e desvios-padrão correspondentes.

\section{RESULTADOS E DISCUSSÃO}

Verificou-se efeito significativo $(\mathrm{P}<0,05)$ da época de colheita dos frutos e da remoção ou não da sarcotesta tanto na velocidade de germinação das sementes de mamão, representada pela germinação aos 15 dias após a semeadura, como na porcentagem final aos 30 dias (Figura 1).

Sementes sem sarcotesta obtidas de frutos colhidos em Julho/2004 apresentaram baixa germinação, com valores de $18 \%$, no $15^{\circ}$ dia, e $27 \%$, no $30^{\circ}$ dia, embora estatisticamente superiores aos verificados para as sementes com sarcotesta, indicando que a presença da sarcotesta contribui para reduzir a germinação das sementes de mamão (Figura 1). Diversos estudos confirmam estas informações, reforçando a hipótese de que a germinação de sementes de mamão com sarcotesta geralmente é inferior a das sementes sem sarcotesta (Lange, 1961; Vazquez, 1969; Gherardi e Valio, 1976; Yahiro, 1979; Yahiro e Oryoji, 1980). No entanto, vários autores relatam a ocorrência de baixa germinação também em sementes sem sarcotesta devido à dormência pós-colheita (Lange, 1961; Yahiro, 1979; Yahiro e Oryoji, 1980; Viggiano et al., 2000; Martins et al., 2005), conforme também constatado no presente trabalho para as sementes desta época de colheita (Julho/2004).
As sementes com sarcotesta extraídas de frutos colhidos em Novembro/2004 (Figura 1) apresentaram também baixa germinação, tanto no $15^{\circ}$ dia (3\%) como no $30^{\circ}$ dia (22\%), conforme verificado para as sementes obtidas de frutos colhidos em Julho/2004. Estes resultados confirmam que a presença da sarcotesta prejudica a germinação das sementes de mamão. No entanto, com a remoção da sarcotesta, houve aumento significativo na germinação das sementes, obtendose valores de 33\% (15 dias) e 68\% (30 dias). Assim pelo valor de germinação obtido no $30^{\circ}$ dia após a semeadura, pode-se afirmar que, em geral, as sementes extraídas de frutos colhidos em Novembro/2004 não apresentaram dormência.

Quando os frutos foram colhidos em Fevereiro/2005 (Figura 1), os menores valores de germinação também foram obtidos para as sementes com sarcotesta tanto aos 15 dias (23\%) como aos 30 dias (67\%). Com a remoção da sarcotesta, a germinação das sementes, no $15^{\circ}$ e $30^{\circ}$ dia, aumentou significativamente, atingindo $67 \%$ e $86 \%$, respectivamente, indicando que a remoção da sarcotesta contribuiu para elevar a germinação. Pelos valores de germinação obtidos, verificase que as sementes sem sarcotesta desta época de colheita não apresentavam dormência, conforme também observado para as sementes colhidas em Novembro/2004 (Figura 1).

A germinação das sementes com sarcotesta extraídas de frutos colhidos em Maio/2005 foi praticamente nula (Figura 1), tanto aos 15 como aos 30 dias, não diferindo significativamente das sementes sem sarcotesta. Estas apresentaram 18\% de germinação (aos 15 e aos 30 dias), indicando a presença de dormência pós-colheita nestas sementes, fato também constatado para as sementes de frutos colhidos em Julho/2004 (Figura 1).

Por outro lado, as sementes sem sarcotesta obtidas de frutos colhidos em Setembro/2005 apresentaram elevada germinação já no $15^{\circ}$ dia (82\%), indicando ausência de dormência (Figura 1). A germinação, aos 30 dias após a semeadura, das sementes de Setembro/2005 também foi alta, ou seja, $88 \%$. Nota-se, contudo, que a germinação das sementes com sarcotesta foi significativamente inferior à obtida para as sementes cuja sarcotesta foi removida, o que também foi constatado nas colheitas de Novembro/2004 e de Fevereiro/2005 (Figura 1).

Verifica-se, portanto, que em todas as épocas de colheita, a germinação das sementes com sarcotesta foi inferior quando comparada com os valores obtidos para as sementes sem sarcotesta (Figura 1). Para Reyes et al. (1980) e Chow e Lin (1991), a sarcotesta apresenta inibidores, principalmente compostos fenólicos, que acarretam germinação lenta e desuniforme das sementes. Assim, germinação satisfatória 
tem sido obtida quando a sarcotesta é removida (Lange, 1961; Gherardi e Valio, 1976; Yahiro, 1979; Pérez et al., 1980; Yahiro e Oryoji, 1980).

As sementes sem sarcotesta extraídas de frutos colhidos em Julho/2004 e Maio/2005 (Figura 1) apresentaram acentuada dormência pós-colheita quando comparadas às sementes colhidas nas demais épocas, com germinação, no $30^{\circ}$ dia, de $27 \%$ e $18 \%$, respectivamente. Diversos autores (Lange, 1961; Yahiro, 1979; Yahiro e Oryoji, 1980; Schmildt et al., 1993 e Viggiano et al., 2000) observaram que mesmo após a remoção da sarcotesta, as sementes de mamão apresentaram dormência pós-colheita.

FIGURA 1. Médias da porcentagem de germinação, no $15^{\circ}$ dia (A) e $30^{\circ}$ dia (B) após semeadura, de sementes com e sem sarcotesta extraídas de frutos de mamão, híbrido Tainung 01, colhidos nos meses de Julho/2004, Novembro/2004, Fevereiro/2005, Maio/2005 e Setembro/2005
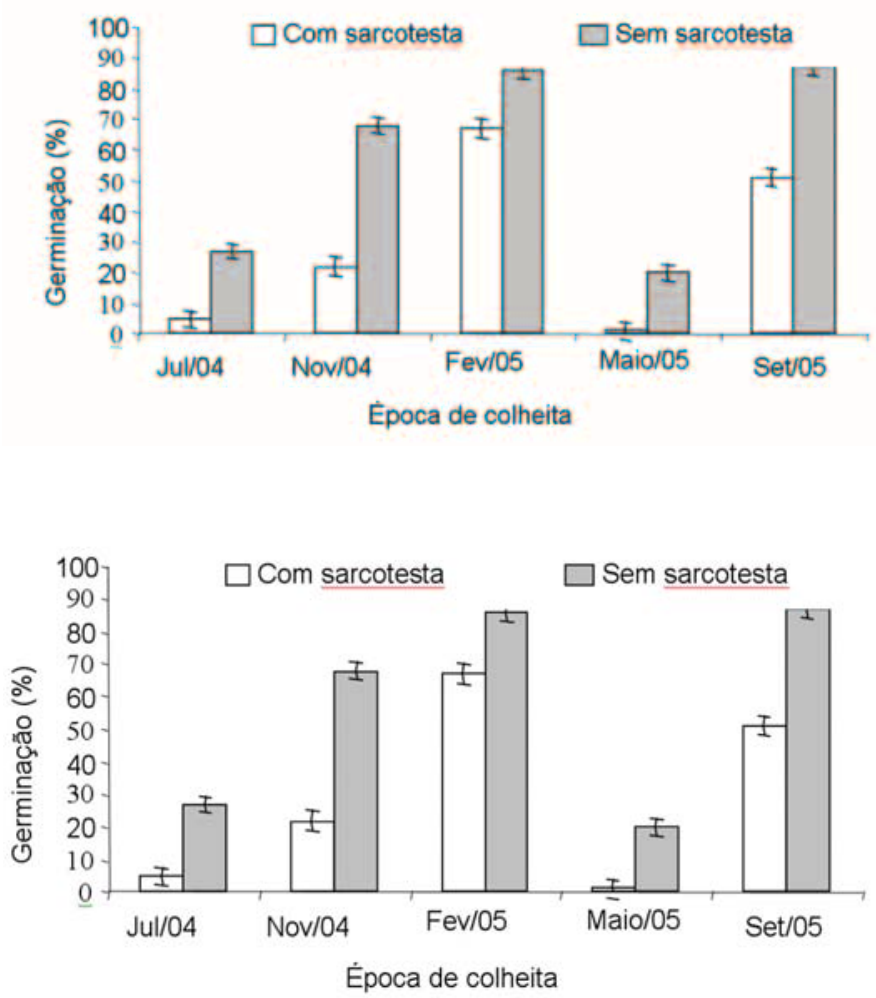

Provavelmente, as condições de ambiente predominantes durante o desenvolvimento e maturação dos frutos influenciaram na intensidade de dormência pós-colheita em sementes de mamão. A dormência pós-colheita depende não só do genótipo, mas também de condições de maturação do fruto e da semente (Carvalho e Nakagawa, 2000). Aroucha et al. (2005), avaliando a influência da época de colheita e do repouso dos frutos na qualidade fisiológica das sementes de mamão, verificaram que as sementes extraídas de frutos colhidos em janeiro apresentaram $40 \%$ de germinação, superior a obtida para as sementes colhidas em setembro $(14,75 \%)$.

Assim, sementes oriundas de frutos que amadureceram em épocas cujas temperaturas foram amenas, especialmente as temperaturas mínimas, ou seja, em Julho/2004 e Maio/2005, apresentaram dormência pós-colheita acentuada (Figura 1), o que não foi constatado para as sementes que se desenvolveram em épocas cujas temperaturas foram mais elevadas (Novembro/2004, Fevereiro e Setembro/2005), conforme pode ser observado pelos dados climáticos apresentados nas Figuras 2 e 3. Nestes meses, as temperaturas médias registradas no município de Linhares - ES foram de $27^{\circ} \mathrm{C}, 26^{\circ} \mathrm{C}$ e $26^{\circ} \mathrm{C}$, respectivamente, com temperaturas máximas acima de $30^{\circ} \mathrm{C}$. Já as temperaturas médias registradas na região nos meses de Maio, Junho e Julho de 2004 foram de $23^{\circ} \mathrm{C}, 22^{\circ} \mathrm{C}$ e $22^{\circ} \mathrm{C}$, respectivamente, sendo que neste período, mesmo as médias das temperaturas máximas registradas nestes meses não ultrapassaram $28^{\circ} \mathrm{C}$, enquanto as mínimas médias foram de $20^{\circ} \mathrm{C}, 17^{\circ} \mathrm{C}$ e $18^{\circ} \mathrm{C}$.

No ano de 2005, nos meses de Abril e Maio, que corresponderam à época de maturação dos frutos, foram registradas temperaturas médias de $25^{\circ} \mathrm{C}$ neste período, com temperaturas mínimas médias de $24^{\circ} \mathrm{C}$ e $21^{\circ} \mathrm{C}$, respectivamente. Segundo Feitosa (1986), o clima na região de Linhares -ES apresenta temperaturas mínimas, no inverno, entre 15 a $18^{\circ} \mathrm{C}$ e temperaturas máximas, no verão, entre 30 e $32^{\circ} \mathrm{C}$. Portanto, é possível afirmar que a ocorrência de dormência pós-colheita em sementes de mamão pode estar relacionada à época de maturação/colheita dos frutos, sendo que sementes obtidas de frutos que amadureceram durante o inverno geralmente apresentam dormência acentuada, ao contrário das sementes que se desenvolveram no verão, sob temperaturas mais altas, que germinaram satisfatòriamente logo após a colheita. Estas informações são importantes para o produtor de sementes no que tange à comercialização dos lotes, já que indicam a necessidade de um período de armazenamento pós-colheita para que a dormência seja superada e as sementes sejam colocadas no mercado com qualidade máxima. O armazenamento das sementes de mamão por determinado período de tempo contribui para a superação 
da dormência (Yahiro, 1979; Aroucha et al., 2005). Segundo Viggiano et al. (2000), a dormência destas sementes foi superada pelo armazenamento por dois meses, independente do ambiente, embalagem e grau de umidade das sementes. Já Aroucha et al. (2004), em sementes da cv. Golden e do híbrido Tainung 01 , verificaram que, independente do estádio de maturação do fruto, foi necessário um período de 8 a 16 meses de armazenamento, respectivamente, para se obter cerca de $80 \%$ de germinação. Mais recentemente, Tokuhisa (2006) observou que sementes dormentes do híbrido Tainung 01 tiveram a dormência superada após o armazenamento por período de 3 a 6 meses.

FIGURA 2-Dados médios, em decêndios, de temperatura máxima e mínima e precipitação, registrados no município de Linhares - ES, durante o ano de 2004.

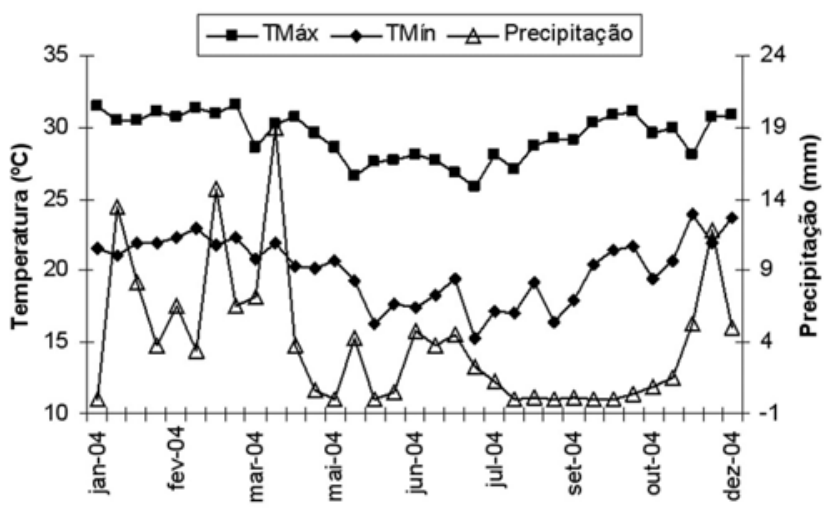

FIGURA 3 - Dados médios, em decêndios, de temperatura máxima e mínima e precipitação, registrados no município de Linhares-ES, durante 0 ano de 2005.

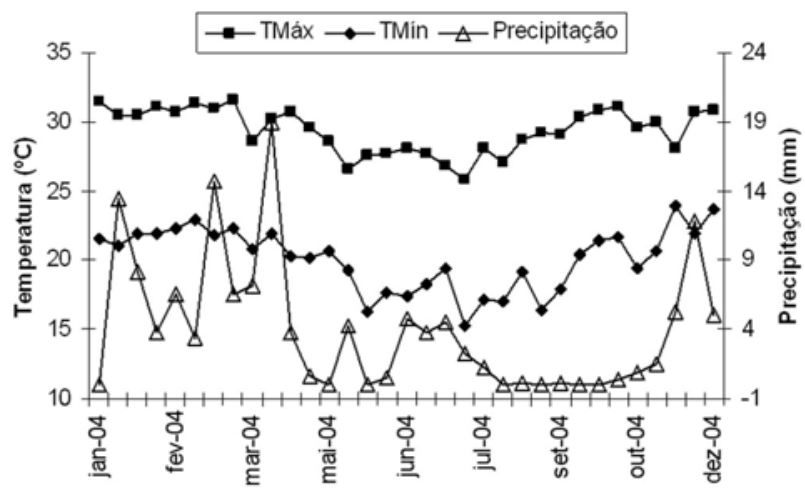

\section{CONCLUSÕES}

A presença da sarcotesta diminui a velocidade e a porcentagem de germinação das sementes de mamão.

A intensidade de dormência das sementes varia com a época de colheita dos frutos, sendo mais acentuada nas sementes extraídas de frutos colhidos no período de temperaturas amenas (Julho/2004 e Maio/2005).

Sementes obtidas de frutos colhidos no período de temperaturas elevadas não apresentam dormência póscolheita.

\section{REFERÊNCIAS}

AGRIANUAL: Anuário da agricultura brasileira. São Paulo: FNP Consultoria e Agroinformativos, 2005. p.241250.

AROUCHA, E.M.M.; SILVA, R.F.; VIEIRA, R.F.; VIANA, A.P.; FREITAS, S.P. Influência do estádio de maturação dos frutos e período de armazenamento das sementes no vigor das sementes de mamão dos grupos Solo e Formosa. In: REUNIÃO DE PESQUISA DO FRUTIMAMÃO, 2., 2004. Anais... Campos de Goytacazes: UENF, 2004. p.71-75.

AROUCHA, E.M.M.; SILVA, R.F.; OLIVEIRA, J.G.; VIANA, A.P.; GONZAGA, M.P. Época de colheita e período de repouso dos frutos de mamão (Carica papaya L.) cv. Golden na qualidade fisiológica das sementes. Ciência Rural, Santa Maria, v.35, n.3, p.537-543, 2005.

BASKIN, C.C.; BASKIN, J.M. Seeds: ecology, biogeography and evolution of dormancy and germination. San Diego: Academic Press, 1998. 666p.

BRASIL. Ministério da Agricultura e Reforma Agrária. Regras para análise de sementes. Brasília, DF: SNDA/ DNDV/CLAV, 1992. 365p.

CARVALHO, N.M.; NAKAGAWA, J. Sementes: ciência, tecnologia e produção. 4. ed. Jaboticabal: FUNEP, 2000. 588p.

CARDOSO, V.J.M. Dormência: estabelecimento do processo. In: FERREIRA, A.G.; BORGHETTI, F. (Ed.). Germinação: do básico ao aplicado. Porto Alegre: Artmed, 2004. p.95-108.

CHOW, Y.J.; LIN, C.H. p-Hydroxibenzoic acid the major phenolic germination inhibitor of papaya seed. Seed Science and Technology, Zürich, v.19, n.1, p167-174, 1991.

DIAS, D.C.F.S. Dormência em sementes: mecanismo de sobrevivência das espécies. Seed News, Pelotas, v.9, n.4, 
p.24-28, 2005.

FEITOSA, L.R. Carta agroclimática do Espírito Santo. Vitória: SEAG-EMCAPA, 1986. 1 mapa, Escala 1:400.000

GHERARDI, E.; VALIO, I.F.M. Occurrence of promoting and inhibitory substances in the seed arils of Carica papaya L. Journal of Horticultural Science, Kent, v.51, n.1, p.114, 1976.

LANGE, A.H., Effect of the sarcotesta on germination of Carica papaya. Botanical Gazette, Chicago, v.122, n.4, p.305-311, 1961.

MARTINS, G.N.; SIILVA, R.F.; OLIVEIRA, A.C.S.; POSSE, S.C.P. Superação da dormência em sementes de mamão.In:PAPAYABRASIL:MERCADOE INOVAÇÕES TECNOLÓGICAS PARA O MAMÃO, 1., 2005. Anais... Vitória: INCAPER, 2005. p.241-243.

PÉREZ, A.; REYES, M.N.; CUEVAS, J. Germination of two papaya varieties: effect of seed aeration, K-treatment, removing of the sarcotesta, high temperature, soaking in distilled water and age of seeds. Journal Agriculture University of Puerto Rico, Río Piedras, v.64, n.2, p.173180, 1980.

REYES, M.N.; PÉREZ, A.; CUEVAS, J. Detecting endogenous growth regulators on the sarcotesta, sclerotesta, endosperm and embryo by paper chromatography on fresh and old seeds of two Papaya's varieties. Journal Agriculture University of Puerto Rico, Río Piedras, v.64, n.2, p.167172, 1980.

SANTOS, R.C.A.; SAMPAIO, L.S.V.; COSTA, J.A. Condição ambiental teor de água e embalagem na viabilidade e no vigor de sementes de mamão. Revista Brasileira de
Sementes, Londrina, v.21, p.194-202, 1999.

SCHMILDT, E.R.; FRONZA, V.; DIAZ, J.L.S.; UNÊDA, S.H.; ALVARENGA, E.M. Comparação de métodos físicos de remoção da sarcotesta e de métodos de secagem de sementes de mamoeiro (Carica papaya L.). Revista Brasileira de Sementes, Campinas, v.15, n.2, p.147-151, 1993.

SINGH, R.M.; SINGH, I.D. Effects methods and duration of storage on seed germination and seedling vigour in papaya. Seed Research, New Delhi, v.9, n.1, p.67-72, 1981.

TOKUHISA, D. Ocorrência e superação da dormência em sementes de mamão (Carica papaya $\mathrm{L}$.) em função da época de colheita dos frutos. 2006. 53f. Dissertação (Mestrado em Fitotecnia) - Universidade Federal de Viçosa, Viçosa.

VAZQUEZ, R.M. Efecto de diversos tratamientos aplicados a la semilla de papaya, sobre su poder germinativo. Agricultura Técnica, Mexico, v.2, n.11, p.487-491, 1969.

VIGGIANO, J.R.; SILVA, R.F.; VIEIRA, H.D. Ocorrência de dormência em sementes de mamão (Carica papaya L.). Sementes Online, Pelotas, v.1, n.1, p.6-10, 2000.

YAHIRO, M. Effects of pre-treatments on the promotion of germination in papaya, Carica papaya L. Memoirs of the Faculty of Agriculture, Kogoshima University, Kagoshima, v.15, n.1, p.49-54, 1979.

YAHIRO, M.; ORYOJI, Y. Effects of gibberellin and cytokinin treatments on the promotion of germination in papaya, Carica papaya L. seeds. Memoirs of the Faculty of Agriculture, Kogoshima University, Kagoshima, v.16, n.1, p.45-51, 1980. 